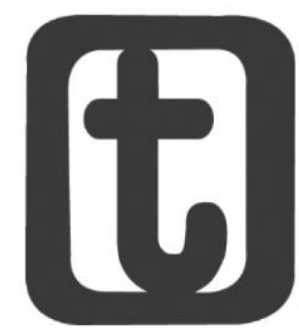

\title{
POLÍTICA SOCIAL DE SAÚDE E FAMÍLIA: ENTRE A PROTEÇÃO E A RESPONSABILIZAÇÃO
}

Health And Family Social Policy: between protection and responsibility

\author{
Bruna Cristina Faustino de Souza* \\ https://orcid.org/0000-0001-6785-368X
}

Ana Maria Santana de Alcântara**

https://orcid.org/0000-0002-0153-5221

\author{
Graziela Acquaviva*** \\ https://orcid.org/0000-0003-2798-1016
}

\section{RESUMO}

A definição de família não é um fenômeno natural, a-histórico e de caráter universal e sim uma criação social e histórica mutável. Um fator que se materializa como unanimidade na história dessa instituição, todavia, é o seu protagonismo na proteção social, especialmente, na área da saúde. O papel da família na preservação da saúde, naquilo que concerne ao encargo pelos cuidados é inegável e requisição fundante para reprodução social. O desmonte das políticas públicas sob a égide do neoliberalismo alavanca, ainda mais, tais requisições. É a partir dessas reflexões, que este artigo tem como objetivos captar a concepção de família e suas diversas configurações, assim como seu papel na proteção social ao longo da história, principalmente, nas políticas públicas de saúde. Como caminho metodológico, se caracteriza como uma pesquisa exploratória, de caráter qualitativo e de cunho bibliográfico. Assim, o artigo está estruturado em dois momentos, onde primeiramente abordamos a família como referência para a proteção social, e em seguida discutimos o papel central dessa instituição nas políticas públicas de saúde no Brasil. Os resultados do estudo, apontam a convocação histórica destinada à família na proteção social global e brasileira, do mesmo modo que evidencia a apropriação do tempo social da figura feminina neste processo. Lógica que também se apresenta

\footnotetext{
* Assistente Social. Especialista em Urgência Emergência. Residência Multiprofissional em Urgência e Emergência Universidade Federal de São Paulo. (UNIFESP, São Paulo, Brasil). R. Botucatu, 740, Vila Clementino, São Paulo (SP), CEP.: 04023-062. E-mail: brunafaus@gmail.com.

** Assistente Social. Mestre em Ciências da Saúde. Assistente Social Universidade Federal de São Paulo/Hospital São Paulo (HSP). (UNIFESP, São Paulo, Brasil). R. Botucatu, 740, Vila Clementino, São Paulo, CEP.: 04023-062. E-mail: ana.santana@huhsp.org.br.

*** Assistente Social. Doutora em Serviço Social. Professora do Departamento de Serviço Social da Faculdade de Ciências Sociais da Pontifícia Universidade Católica de São Paulo. (PUCSP, São Paulo, Brasil). R. Monte Alegre, 984, Monte Alegre, São Paulo (SP), CEP.: 05014-001. E-mail: acquaviva@pucsp.br.
}

DOI 10.22422/temporalis.2021v21n41p270-285 Commons Atribuição 4.0 Internacional (https://creativecommons.org/licenses/by/4.o/deed.pt_BR), que permite copiar e redistribuir o material em qualquer suporte ou formato, bem como adaptar, transformar e criar a partir deste material para qualquer fim, mesmo que comercial. O licenciante não pode revogar estes direitos desde que você respeite os termos da licença. 


\section{temporalis}

nos serviços de saúde e revela a faceta da desresponsabilização do Estado em detrimento à responsabilização de famílias.

\section{PALAVRAS-CHAVE}

Família. Proteção Social. Política de Saúde.

\section{ABSTRACT}

The definition of family is not a natural, ahistorical and universal character, but a mutable social and historical creation. A factor that materializes unanimously in the history of this institution, however, is its leading role in social protection, especially in the area of health. The role of the family in the preservation of health, regarding the responsibility for care, is undeniable and a fundamental requirement for social reproduction. The unmounting of public policies under the aegis of neoliberalism further leverages such requests. Based on these reflections, this article aims to capture the concept of family and its various configurations, as well as its role in social protection throughout history, especially in public health policies. As a methodological path, it is characterized as an exploratory, qualitative and bibliographical research. Thus, the article is structured in two moments, where we first approach the family as a reference for social protection, and then we discuss the central role of this institution in public health policies in Brazil. The results of the study point to the historical summons assigned to the family in global and Brazilian social protection, as well as showing the appropriation of social time by the female figure in this process. Logic that also presents itself in health services and reveals the facet of the State's de-responsibility in detriment to the accountability of families.

\section{KEYWORDS}

Family. Social Protection. Health Policy.

Submetido em: 22/3/2021.

Aceito em: 15/6/2021.

\section{INTRODUÇÃO}

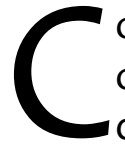

ompreender o delineamento da instituição família, admitindo, antes de mais nada, o quanto o seu conceito é polissêmico e complexo é essencial para o debate. A definição de família, portanto, não é um fenômeno natural, a-histórico e de caráter universal, pelo contrário, é uma criação social e histórica mutável, que se define e se transforma conforme a estrutura social dada. Deste modo, sua concepção decorre diretamente da organização da sociedade e de seus determinantes estruturais (CARLOTO, 2005).

Ribeiro (1999 apud STAMM; MIOTO, 2003) concorda que a conceituação de família é tarefa complexa e nos convida a refletir que essa análise possui ainda mais entraves, quando o sujeito que se empenha em realizá-la utiliza como parâmetros seus próprios valores, crenças e experiências pessoais. Há uma tendência, conforme preconiza a autora, de conceituarmos família a partir de nossas próprias famílias. Assim, é mais que primordial destacar que devemos nos despir de nossas referências pessoais para pensar essa instituição, uma vez que não podemos falar em um único conceito de família, muito menos propiciar raciocínios em torno desta discussão que transformem diferenças em desigualdades ou incompletudes.

Quando olhamos para a história, pensar sobre família nos exige refletir sobre a construção e a reconstrução de conceitos ao longo dos séculos, amplamente disseminados pelas ciências sociais. O constructo sobre a família brasileira nesta área de conhecimento, contudo, como pontuado por Bertelli e Moser (2018), estabeleceu-se sob um terreno fértil para determinismos e generalizações. Este campo de estudo, recorrentemente, pautou

Temporalis, Brasília (DF), ano 21, n. 41, p. 270-285, jan.jun. 2021. | ISSN 2238-1856 
sua compreensão sobre famílias em construções que dialogam com a lógica europeia, no entanto, quando usamos tais referenciais para compreender a família brasileira, identificamos obstáculos importantes.

No período anterior à chegada do colonizador em território brasileiro, a população indígena, por exemplo, já desenvolvia sua sociabilidade e, portanto, suas formas de organização, que resultavam em modelos próprios de família. Prática esta, que se estendeu à chegada do povo africano, escravizado e sequestrado para nosso país, que também estabeleceu formas de organização particular, apesar dos limites postos ${ }^{1}$, resultando em referências de famílias. Entretanto, foi o modelo europeu dos colonizadores que se impôs como modelo social de família.

Este modelo, contudo, encontrou uma aplicabilidade extremamente restrita para realidade brasileira. Essa contradição, inclusive, pode ser vislumbrada em diversas situações, onde observamos a tensão entre a família "pensada" e a família "vivida" (SKYMANSKI, 1992). Um exemplo que nos salta os olhos, no que diz respeito a tal problemática, materializa-se no conceito de mulheres se dedicarem exclusivamente ao mundo privado, no modelo de família "institucionalizado", em contraponto a atribuição da chefia de família à mulheres, assim como, a ausência da figura masculina nas configurações familiares, fatos recorrentes na realidade de nosso país. Como declara Bertelli e Moser (2018): "a dita inclusão das mulheres no mercado de trabalho nunca foi novidade para as mulheres negras e pobres".

Um fator, contudo, que se materializa como unanimidade na história das famílias no Brasil e no mundo, é o protagonismo dessa instituição no contexto da proteção social. Barcelos (2011) nos alerta que ao observar as contribuições das diversas disciplinas científicas, especialmente das ciências sociais, podemos perceber inúmeras definições que centram seus interesses na família enquanto lócus de proteção social.

A família, ao longo da história e em diferentes sociedades, exerceu papel fundante no desenvolvimento da proteção social. Lima (2006 apud BARCELOS, 2011) ressalta, inclusive, que a relação entre família e proteção social cruza a história da humanidade e está inteiramente vinculada aos aspectos políticos, sociais, culturais e econômicos que compõem a vida em sociedade.

Partindo deste pressuposto e dos referenciais teóricos estabelecidos em torno desta temática, este artigo tem como caminho metodológico, a elaboração de uma pesquisa exploratória, de caráter qualitativo e de cunho bibliográfico, que visa compreender as contradições inerentes a discussão da instituição família, que tem se caracterizado como uma verdadeira parceira do poder público, no que diz respeito às práticas de cuidado, especialmente àquelas vinculadas à saúde. Cenário este que se potencializou ainda mais na conjuntura neoliberal, que alavancou o subfinanciamento e a precarização das políticas sociais em nosso país e em todo mundo.

\footnotetext{
${ }^{1} \mathrm{O}$ "excesso de homens sobre as mulheres, a separação das famílias no tráfico interno de escravos, os caprichos e as violências dos senhores" complexificavam a manutenção de uma organização familiar entre as pessoas escravizadas, mas não impediam que elas acontecessem (SLENES, 1988).
} 


\section{tempordlis}

Para tanto, o artigo está estruturado em dois momentos, onde primeiramente abordamos a família como referência para a proteção social, e em seguida discutimos o papel central dessa instituição nas políticas públicas de saúde no Brasil.

\section{A FAMÍLIA COMO REFERÊNCIA PARA A PROTEÇÃO SOCIAL: REALIDADE GLOBAL E BRASILEIRA}

Ao falarmos de políticas sociais é primordial compreender, antes de mais nada, sua articulação com a política econômica e a luta de classes, resultado de relações complexas e contraditórias estabelecidas entre Estado e sociedade civil, desenvolvidas no processo de produção e reprodução do capitalismo. O antagonismo capital e trabalho demarca a condição histórica e social das políticas sociais e confere o contraste de sua natureza: "A política social é resultado da luta de classes e ao mesmo tempo contribui para a sua reprodução" (NETTO, 2005, p. 59 apud BARCELOS, 2011, p. 25).

Assim, as políticas sociais assumem por um de seus ângulos, a função de garantir a reprodução da força de trabalho e elevar a produtividade do capital, assegurando a manutenção do status quo, mas também, do mesmo modo, podem ser centrais na agenda de lutas dos trabalhadores e no cotidiano de suas vidas, quando conseguem garantir ganhos para essa classe e impor limites aos ganhos do capital (BEHRING; BOSCHETTI, 2007, p. 38).

A relação da família com os sistemas de proteção social é tema de ampla discussão, tendo destaque neste contexto a investigação sobre o papel das famílias na reprodução social, assim como as condições em que tal realidade se constrói. É possível vislumbrar a ampliação desse debate a partir da década de 1970, especialmente no que concerne à categoria trabalho, que ganhou espaço no escopo dos estudos feministas de orientação marxista.

Tal fato permitiu possibilidades de análise sobre a família, não só em sua relação com o mercado, mas, também em sua relação com o Estado. Além disso, viabilizou a compreensão de que a família, através do trabalho não remunerado de mulheres, se estrutura como um dos pilares do Estado de bem-estar social em diversos países, determinando-se não só como unidade social fundamental para a sociedade, mas também como unidade econômica na distribuição de bens e serviços (MIOTO, 2015, p. 703).

Alguns autores, inclusive, passaram a tipificar as principais tendências de incorporação da família no campo da política social, tendo como premissa o peso dessa instituição na reprodução do bem-estar. Atualmente, a grosso modo, considera-se duas principais referências em disputa para se refletir o papel da família na proteção social, sendo elas a proposta familista e a proposta protetiva como sugere Mioto (2010) ou o familismo e a desfamilização como afirma Esping-Andersen (1991).

A proposta familista, delineada no interior do desenvolvimento capitalista e do liberalismo econômico entre os séculos XVIII e IX, reside na perspectiva da existência de dois canais naturais para a satisfação de necessidades dos indivíduos: a família e o mercado. É apenas quando esses canais falham, que a interferência pública por parte do Estado deve ocorrer 
e, ainda sim, de maneira transitória. Ou seja, a incorporação da família na política social neste ideal, se coloca através da falência dessa instituição, esquematizando uma proteção social compensatória e temporária com uma menor provisão de bem-estar por parte do Estado.

O familismo ou um Estado de bem-estar familiarista é aquele que designa o máximo de obrigações de bem-estar para a unidade familiar. Neste sistema, "as políticas públicas consideram - na verdade insistem - que as unidades familiares devem assumir a principal responsabilidade sobre seus membros" (ESPINGANDERSEN, 1991, p. 66 apud BARCELOS, 2011, p. 34).

Neste bojo, também é possível notar a disseminação da culpabilização das famílias por sua incapacidade de gerir e otimizar recursos, assim como de desenvolver estratégias para sua manutenção. Neste cenário, as dificuldades de provisão de bem-estar advindas, por exemplo, do desemprego ou do adoecimento, passam a ser consideradas "problemas" da família e não questões estruturais permeadas pela configuração de uma sociedade pautada sob a égide do capitalismo, do patriarcado e do racismo.

Neste contexto, assistimos a desresponsabilização, cada vez mais acentuada, do Estado na garantia dos direitos sociais, transmutada na focalização das políticas sociais, como destaca Mioto (2010a):

\begin{abstract}
A crítica mais contundente à afirmação da família como referência das políticas públicas, na atualidade, está associada à regressão da participação do Estado Social na provisão de bem-estar. Ou seja, desvia da rota da garantia dos direitos sociais através de políticas públicas de caráter universal e entra na rota da focalização das políticas públicas nos seguimentos mais pauperizados da população, fortalece significativamente o mercado enquanto instância de provisão de bem-estar e aposta na organização sociedade civil como provedora. Nessa configuração a família é chamada a reincorporar os riscos sociais e com isso assiste-se um retrocesso em termos de cidadania social (MIOTO, 2010a, p. 170).
\end{abstract}

A proposta protetiva (ou desfamilização), por sua vez, consiste na afirmação da proteção social mediante a garantia de direitos sociais universais. Esping-Andersen (1991) conceitua a desfamilização como o abrandamento da responsabilidade familiar em relação a provisão de bem estar social, mediante a disponibilização de medidas via Estado ou da provisão do mercado: “[...] aquelas políticas que reduzem a dependência individual da família e que maximizam a disponibilidade de recursos econômicos por parte do indivíduo independente das reciprocidades conjugais e familiares" (ESPING-ANDERSEN, 1991, p. 66 apud BARCELOS, 2011, p. 35).

A presença do Estado neste ideal pressupõe, portanto, a diminuição dos encargos familiares, possibilitando políticas sociais em uma perspectiva que visa "[...] socializar antecipadamente os custos enfrentados pela família, sem esperar que a sua capacidade se esgote" (MIOTO, 2010a, p. 171).

As duas tendências expostas apresentam o tensionamento dos projetos no campo da proteção social em voga ao longo da história da humanidade e, especialmente, nos dias atuais, o que representa um impacto direto no desenvolvimento de políticas públicas em todos os seus níveis, ou seja, desde sua formulação até seu processo de implementação e 


\section{tempordilis}

execução.

Campos e Mioto (2003, p. 168) nos apresentam, ainda, uma segunda tipificação que revela a posição da família nos distintos sistemas de proteção social: 1) a família nos sistemas de proteção social de orientação social-democrata; 2) a família do provedor masculino; e 3) o sistema de proteção social familista.

Nos sistemas de proteção social de orientação social-democrata, o Estado socializa antecipadamente os custos enfrentados pela família sem esperar que a sua capacidade se esgote, o que diminui os encargos sobre a família. Já a família do provedor masculino é comum nos países de Estado de Bem-Estar Social onde a referência é o trabalhador assalariado, e pauta os benefícios na família do trabalhador masculino; nesse sistema cabe à mulher o cuidado dos filhos e da casa. No sistema de proteção social familista, a família assume a responsabilidade pelo bem-estar de seus membros (CAMPOS; MIOTO, 2003, p. 168-175).

Quando pensamos na incorporação da família nas políticas sociais na realidade brasileira, é importante atentar ao fato de nosso país nunca ter experimentado um regime de estado semelhante ao de bem-estar social, o que imprime características próprias para nossa proteção social, merecendo destaque a focalização - com ações direcionadas à população pauperizada - em detrimento a universalidade.

A constituição do processo do sistema de proteção social foi marcada pela estrutural desigualdade socioeconômica, voltada à população empobrecida, excluída do mercado formal de trabalho, como modelo centrado no trabalhador urbano juntamente a uma estrutura assistencial meritocrática de distribuição (MIOTO; CAMPOS; LIMA, 2006, p. 170)

Apesar de não ter experimentado o "Estado de Bem Estar Social”, o Brasil, na década de 1980 trava uma luta popular em prol da democracia, luta essa, que culminou na Constituição Federal de 1988. Entre as principais conquistas deste documento, podemos citar a instituição do sistema de seguridade social. No entanto, tais ganhos não foram suficientes para lidar com os desmontes previstos pela ideologia neoliberal executada no Brasil à partir da década de 1990, inviabilizando o direcionamento progressista da Carta Magna e processando o que denominamos como contra-reforma do Estado (BEHRING; BOSCHETTI, 2007).

Desde então, o desmonte de tais políticas vêm sendo realizado sob o argumento da crise fiscal que o Estado enfrenta, sendo os gastos sociais ditados pela lógica econômica (IAMAMOTO, 2015). Assim, a seguridade social, pode ser apontada como uma das principais afetadas por tal ofensiva, tendo destaque a política de saúde, objeto de nossas reflexões neste estudo.

É possível afirmar que a proteção social brasileira foi se desenhando, ao longo da sua história, sob o caráter familista, assim, mesmo com a tentativa de universalização de direitos advinda da idealização da constituição cidadã, não podemos deixar de frisar a significativa expectativa do protagonismo das famílias na provisão do bem-estar social em nosso país e consequentemente, a responsabilização destinada a esta instituição no 
campo das políticas sociais:

\begin{abstract}
Diante disso, pode-se dizer que a partir dos anos 1990 se acirra no Brasil um processo de disputa entre diferentes projetos políticos para a sociedade brasileira, nos quais a questão da proteção social joga papel fundamental. Nesse âmbito, o processo é caracterizado, por um lado, pela tensão entre a afirmação da proposta de institucionalização da proteção social nos moldes definidos pela Constituição de 1988 e a sua desconstrução através da retração do Estado. Esta inclui tanto as privatizações como a adesão ao princípio da focalização nas políticas públicas e a afirmação do pluralismo de bem-estar. Por outro lado, pela tensão entre a afirmação da família como parceira na condução das políticas sociais e a sua 'desfamiliarização'. Mesmo com os avanços advindos da Constituição de 1988, a regulamentação das diferentes políticas sociais [...] ainda pautou a família como ator importante na provisão de bem-estar (MIOTO, 2008, p. 143).
\end{abstract}

É importante pontuar que a convocação das famílias na condução das políticas sociais se destaca, inclusive, no aparato legislativo dos diversos países. No Brasil, nossa constituição tem uma declarada concepção familista, que responsabiliza e onera essa instituição (CAMPOS; MIOTO, 2003). Assim, por mais que se reconheçam os avanços, é fundamental destacar que as políticas sociais nos países pobres, ainda são orientadas pelos ditames dos organismos internacionais, com critérios que reiteram a focalização, a privatização e a transferência de ações e serviços para o mercado e sociedade civil, essencialmente, às famosas Organizações Não Governamentais e à família (BOSCHETTI, 2009).

Deste modo, podemos ressaltar que as configurações das políticas sociais no Brasil nos últimos anos foram construídas a partir do corte de gastos estatais na direção do projeto neoliberal, tendo destaque em sua condução a focalização, a privatização e a participação da sociedade civil em sua execução. Tal contexto ampliou de forma ainda mais significativa, a já existente requisição de famílias na provisão da proteção social em nosso país, como reitera Barcelos (2011):

\footnotetext{
Apesar de, no Brasil, a família sempre ter tido um papel de destaque na provisão da proteção social de seus membros, a crise do Estado de Bem-Estar, em escala global, implicou na ênfase da autonomia familiar como possibilidade de atender suas necessidades. Pretendeu-se transformar a família em recurso para todas as dificuldades do mundo globalizado e de uma sociedade de riscos. Dessa forma, mesmo que em proporções diferentes nos diferentes países, ocorreu a supervalorização da família no âmbito das políticas sociais (BARCELOS, 2011, p. 32).
}

Algumas materializações da incorporação das famílias na provisão do bem-estar social no Brasil podem ser exemplificadas pelas características de determinadas políticas públicas. A Política Nacional de Assistência Social (PNAS), datada do ano de 2004, por exemplo, tem como uma de suas diretrizes a preconização de que a família deverá ter a centralidade para a concepção e a implementação dos benefícios, serviços, programas e projetos. A matricialidade sociofamiliar também se apresenta como base de organização do Sistema Único de Assistência Social (SUAS).

A concepção de família exposta no documento, apesar de estar mais aberta e ampla, por compreender diversos arranjos familiares, ainda mantém as mesmas expectativas sobre o 


\title{
tempoorlils

papel da família e suas responsabilidades enquanto um grupo/arranjo de proteção e cuidados dos indivíduos, principalmente no que se refere ao papel da mulher/mãe, encarado como o principal elemento provocador de mudanças, tendo um papel ativo para a configuração de uma boa família.

Assim, não é raro vislumbrar como as famílias - e mais especificamente, como as mulheres - são responsáveis pelo cumprimento de determinadas condicionalidades para a efetivação de acesso à direitos sociais e como o trabalho do conjunto de serviços da seguridade social são, geralmente, direcionados a esta instituição e a sua capacidade de se reinventar para superar sua condição, considerada, muitas vezes, disfuncional. Tal fato expõe a contradição latente entre a proteção e a responsabilização, observadas na política de assistência social:

\begin{abstract}
Atualmente, por exemplo, a família assume centralidade para o desenvolvimento da política de assistência social, numa perspectiva contraditória, em que se oferece proteção e se reconhece a variedade de experiências familiares, mas em contrapartida continua-se com o reforço da responsabilização pela educação e criação dos filhos, sem os apoios devidos da sociedade, além da gestão de problemas que extrapolam sua capacidade (CAMPOS; TEIXEIRA, 2010, p. 26)
\end{abstract}

Segundo Campos e Teixeira (2010) os encargos familiares com a proteção social no Brasil também podem ser medidos pelo subdesenvolvimento da rede de serviços dirigidos à família, desprezada, no Brasil, em função da ênfase em transferências financeiras, que impõem restrições significativas aos gastos públicos com as políticas sociais:

\footnotetext{
Em relação aos serviços de creches, para o total de crianças de zero a três anos de idade, segundo o IBGE (2006), a frequência era de apenas 13,3\%. Este acesso era ainda mais restritivo às famílias pobres, com rendimentos de até $1 / 2$ salário mínimo per capita, com um percentual de $8,6 \%$, bem abaixo da média, enquanto que, para as crianças de famílias com rendimento acima de três salários mínimos a taxa chegava a 35,8\%. Este é certamente um fator de restrição ao trabalho das mulheres no mercado e de ampliação da sua carga horária semanal de serviços domésticos. Isso sem contar a insuficiência de serviços domiciliares de atendimento aos idosos dependentes, crianças com deficiência, serviços de ocupação do tempo livre, de socialização, de formação para a cidadania, de capacitação para o mercado de trabalho para jovens, adultos sem emprego, dentre outros eventuais membros das famílias (CAMPOS; TEIXEIRA, 2010, p. 2526).
}

O caráter familista da política social brasileira se destaca e revela como o Estado continua definindo suas propostas de intervenção com base na capacidade dessa instituição de se reinventar, proteger e cuidar de seus membros, deixando de assumir, assim, sua função de garantia da proteção social. A fase neoliberal do capital, por sua vez, acirra ainda mais tais relações, restringindo os investimentos sociais e projetando medidas de solidariedade social, onde o papel da família merece destaque. Vislumbramos, deste modo, como a família é colocada, cada vez mais, como um recurso para o suprimento das dificuldades do mundo globalizado e de uma sociedade de riscos e o quanto tal proposta mostra-se questionável. 


\section{A FAMÍLIA NA POLÍTICA PÚBLICA DE SAÚDE NO BRASIL: PROTAGONISMO OU RESPONSABILIZAÇÃO?}

A saúde brasileira, historicamente, se configurou como excludente e médico centrada, tendo, deste modo, a profunda marca da desigualdade social e o predomínio do olhar biologicista e mercadológico. É apenas na década de 1970 que tal realidade ganha relevos significativos, com o advento do projeto de Reforma Sanitária Brasileira (RSB), movimento que se construiu tendo como elemento central a discussão sobre o binômio saúde e doença, compreendendo que tal conceito é estabelecido a partir de determinantes e condicionantes sociais, marcados pelas relações de classe, gênero e raça/etnia. A concepção de um Estado democrático de direito que assegura a universalidade do acesso às políticas públicas também marca a perspectiva adotada por tal projeto (MOTA et al., 2009).

Na esteira dessas discussões, vislumbramos em 1988 o advento da constituição federal "cidadã" e o surgimento do tripé da seguridade social, elementos que alteraram de forma significativa o campo das políticas públicas em nosso país. Como fruto das mobilizações estabelecidas pelo projeto de Reforma Sanitária Brasileira, no campo da saúde, temos o nascimento do Sistema Único de Saúde e sua regulamentação com as Leis 8.080 e 8.142/1990, que transformaram este setor no Brasil, com a preconização de um sistema universal, integral, gratuito e equânime.

A reforma sanitária, entretanto, não foi contemplada em sua magnitude, enquanto projeto societário, ainda que tenha obtido ganhos quando participou da constituinte e conquistou cinco artigos que contemplam a saúde como direito de todos e dever do Estado - apesar de um destes, deixar livre a saúde para iniciativa privada. Os artigos, que apresentavam a centralidade das ações de promoção, proteção e recuperação da saúde, diferente do foco curativista, contudo, antes mesmo que pudessem ser efetivados, conviveram com importante limites ditados pela hegemonia neoliberal que arrebatou a lógica deste setor em nosso país (VASCONCELOS, 2012).

Desde então, assistimos não só um giro de concepção na saúde pública brasileira, mas, também, a acirrada disputa que se estabeleceu entre o projeto de reforma sanitária brasileira e o projeto privatista, articulado ao mercado, que sempre obteve grandes conquistas diante do fundo público. A hegemonia neoliberal limitou, de forma fundante, a implantação de um sistema de saúde de qualidade, que pudesse, de fato, valer os princípios de universalidade, integralidade e equidade, o que evidencia, cada vez mais, a incompatibilidade do bem estar social da classe trabalhadora com o acúmulo de riquezas, que apesar de ser socialmente produzido, é apropriado de forma cada vez mais privada (IAMAMOTO, 2015).

Conforme destaca Bravo (2008), nesse cenário político convivem, na saúde, dois projetos em tensão: o projeto privatista, hegemônico na segunda metade da década de 1990, que é aquele em que há o avanço do complexo médico-industrial em direção à retração dos direitos referentes à saúde, tendo em vista que a saúde fica vinculada ao mercado, com ênfase em parcerias com a sociedade civil, havendo, assim, a precarização da saúde no âmbito público; e em outra direção, o projeto de Reforma Sanitária, construído na década de 1980 e inscrito na 
constituição de 1988, que propõe a justa e equitativa distribuição de bens e serviços de saúde, de acesso público universal e integral. Na atualidade, a ênfase na focalização, no desfinanciamento, na precarização e na terceirização dos recursos humanos tem caracterizado a política de saúde brasileira (BARCELOS, 2011, p. 44).

Nosso país, que ocupa o ranking de $7^{\circ}$ país mais desigual do mundo conforme relatório do Programa das Nações Unidas para o Desenvolvimento (PNUD) de 2019, demanda um sistema de saúde que efetive os princípios da integralidade, da universalidade e da equidade. E mais, que tenha uma concepção de saúde que corresponda a realidade material vivenciada pela população usuária, tendo destaque nesta discussão o conceito ampliado de saúde em detrimento do ideal de ausência de doenças.

Ainda sim, é fundamental pontuar que, apesar de todos problemas enfrentados para sua implementação, o SUS se coloca atualmente como o maior responsável pela realização de procedimentos em saúde do país, sendo que cerca de $80 \%$ dos brasileiros são SUSdependentes - fora os demais, que acessam este sistema em outras instâncias, tendo destaque às vigilâncias em saúde². Todavia, tal sistema de saúde, mesmo após cerca de 30 anos de sua implementação, ainda se alicerça, em grande parte, sobre a rede de serviços privados, o que comprova a tese de um sistema dual (BARCELOS, 2011).

O acesso à proteção social, ou seja, aos bens e serviços oferecidos pelo Estado,
tem analogia direta com o projeto político ao qual o Estado está vinculado.
Percebe-se a dicotomia entre os preceitos da legislação vigente da política de
saúde e a prática real dessa política. Nesses vinte anos de SUS, observaram-se
avanços e retrocessos convivendo numa trama de lutas, através dos movimentos
sociais e da sociedade civil, e de perdas significativas com a deterioração do
sistema público e com os serviços organizados de forma segmentada
(BARCELOS, 2011, p. 47).

O desmonte das políticas públicas sob a égide do neoliberalismo e seus corolários privatização, focalização e precarização - requisita a criação de um conjunto de estratégias, para a garantia da reprodução social, em um contexto de insuficiência de intervenções do Estado. Uma dessas estratégias se materializa na apropriação do tempo social das famílias, instituição que possui espaço extremamente significativo no campo da saúde pública brasileira ao longo de toda sua história.

A família, conforme nos aponta Nogueira (2002), no contexto de desmonte da saúde pública, é redescoberta como elemento imprescindível à compreensão do processo saúdedoença e como sujeito fundamental na responsabilidade pelo cuidado. Destaca-se, neste processo, a utilização da capacidade familiar, indicada pelas agências internacionais, que começam a valorizar o papel dessa instituição na conservação da saúde doméstica e na cura dos doentes.

A família, deste modo, tem se caracterizado, cada vez mais, como uma verdadeira parceira

\footnotetext{
${ }^{2}$ A Pesquisa Nacional de Saúde (2013) revela que a maioria da população (estima-se que $80 \%$ ) é SUSdependente para as ações relacionadas à assistência à saúde [...]. Contudo, seu caráter universal é mais evidente nas ações de vigilância em saúde, que alcançam a totalidade da população brasileira (DUARTE; EBLE; GARCIA, 2018, p. 1)
} 
do poder público no que diz respeito às práticas de cuidado vinculadas à saúde, especialmente, quando compreendemos o subfinanciamento e a precarização deste setor em nosso país. A família, neste sentido, apresenta-se como um braço do Estado, responsabilizando-se, inclusive, em alguns casos, pela insuficiência de recursos humanos e materiais.

Ao observarmos o processo de universalização da política de saúde no Brasil, em que pese seus limites e contradições, vislumbramos o recorrente uso de estratégias de participação da família e o engajamento das comunidades em iniciativas de promoção e saúde preventiva. Diversas estratégias governamentais, a partir da década de 1990, apontam essa relação, merecendo destaque o conhecido Programa de Saúde da Família, que incide, de forma relevante, na provisão e organização do cuidado protagonizado pela família.

\begin{abstract}
O Programa Saúde da Família (PSF) é a estratégia em torno da qual se organiza a política de atenção básica. Diversos estudos foram produzidos sobre as contradições inerentes a este processo, a exemplo da dualidade público-privado no interior do Sistema Único de Saúde (SUS), da tensão entre universalização e focalização, entre desfamiliarização e familiarização da atenção (SOARES, 2010) no bojo da humanização da saúde. Uma dimensão, entretanto, permaneceu em grande medida invisibilizada no debate sobre os descaminhos das políticas sociais de saúde sob a égide do neoliberalismo e do neodesenvolvimentismo: a permanência de grande parte dos encargos sobre as famílias e, no interior desta esfera, sobre as mulheres, determinação da divisão sexual do trabalho que estrutura as relações sociais de sexo (FERREIRA, 2017, p. 21).
\end{abstract}

Outros dispositivos e as diretrizes oficiais passaram a fazer menção à família e explicitar a requisição da organização e provisão do cuidado por esta instituição, evidenciando-se, neste processo algumas iniciativas, como: a Política Nacional de Humanização; as Diretrizes Operacionais do Pacto pela Saúde; o Guia Prático do Cuidador; a cartilha "Visita Aberta e Direito a Acompanhante"; a Política de Atenção Humanizada ao Recém - nascido de Baixo Peso - Método Canguru e Rede Cegonha (BARCELOS, 2011).

Um dos exemplos marcantes no que diz respeito à provisão do cuidado por parte da instituição família reside no texto do "Guia Prático do Cuidador". Este material elege a família como elemento primordial para ministrar o cuidado e, de certo modo, naturaliza este processo, desvalorizando as implicações e condições objetivas para tal atribuição. A descrição do cuidador, contida em tal material, evidencia essa problemática:

[o cuidador] é um ser humano de qualidades especiais, expressas pelo forte traço de amor à humanidade, de solidariedade e de doação. A ocupação de cuidador integra a Classificação Brasileira de Ocupações - CBO sob o código 5162, que define o cuidador como alguém que "cuida a partir dos objetivos estabelecidos por instituições especializadas ou responsáveis diretos, zelando pelo bem-estar, saúde, alimentação, higiene pessoal, educação, cultura, recreação e lazer da pessoa assistida". É a pessoa, da família ou da comunidade, que presta cuidados à outra pessoa de qualquer idade, que esteja necessitando de cuidados por estar acamada, com limitações físicas ou mentais, com ou sem remuneração. Nesta perspectiva mais ampla do cuidado, o papel do cuidador ultrapassa o simples acompanhamento das atividades diárias dos indivíduos, sejam eles saudáveis, enfermos e/ou acamados, em situação de risco ou fragilidade, seja nos domicílios e/ou em qualquer tipo de instituições na qual necessite de atenção ou cuidado diário (BRASIL, 2008, p. 8). 


\section{temporalis}

Outro exemplo a ser citado é o funcionamento do Programa Melhor em Casa, voltado para o atendimento de pessoas com necessidade de reabilitação motora, idosos, pacientes crônicos sem agravamento ou em situação pós-cirúrgica que terão assistência multiprofissional gratuita em seus lares, com cuidados mais próximos da família (BRASIL, 2012). Este programa compõe a redefinição da atenção domiciliar no SUS e é regulado pela Portaria n. 2.527 de 2011, que determina como foco central de sua proposta as responsabilidades do cuidador e sua relação com a equipe multiprofissional que irá oferecer assistência aos pacientes. Das nove atribuições previstas pela Portaria para a equipe multiprofissional seis delas se referem diretamente ao preparo/capacitação do cuidador, que pode ou não ser um membro da família.

O Programa Melhor em Casa explicita oficialmente a incorporação das famílias na gestão do cuidado em saúde, que se caracteriza como uma atribuição fundante dos serviços de saúde. Essa incorporação se expressa no número de atribuições previstas pela Portaria n. 2.527 de 2011 emitida pelo Ministério da Saúde para o preparo/capacitação do cuidador pela equipe multiprofissional e a exigência da indicação de um cuidador por parte da família, nos casos de maior complexidade, conforme previsto na modalidade Atenção Domiciliar 2 e 3.

Outros tantos documentos, confeccionados pelo Ministério da Saúde, indicam que a política de saúde conta com a família para sua execução e manutenção. A contribuição das famílias se materializa de diversas formas, tendo destaque nesta discussão, um nebuloso campo de indefinições e negociações, definidos por Mioto (2010b) como campo do cuidado:

\footnotetext{
É justamente nesse campo que ocorrem, no cotidiano dos serviços, os deslizamentos em torno de atribuições de responsabilidades na provisão de bem estar. Sob a égide do cuidado se articulam diferentes estratégias de imposição ou transferência dos custos do cuidado para as famílias. Tais custos situam-se tanto no arco dos custos financeiros, como emocionais e de trabalho. [...] as famílias não se encontram nas mesmas condições materiais e culturais, e com isso as possibilidades de usufruírem dos serviços também se tornam desiguais. Tanto para avaliá-los e negociar sobre as condições e qualidade dos serviços ofertados, quanto para a combinação de recursos para usufruir dos serviços. Essa combinação implica tanto em trabalho familiar, como em recursos materiais da família que inclui os auxílios da rede social primária família extensa (MIOTO, 2010b, p. 5).
}

Neste bojo, refletimos como a orientação familista e maternalista dos serviços de saúde, antes de se materializar em uma orientação ideológica ou um reforço a papéis sociais naturalizados, repousa em um fato concreto: "[...] a apropriação do tempo social e das práticas constituintes da reprodução privada, em mecanismo de ação do Estado" (FERREIRA, 2017, p. 21-22). Do mesmo modo, FERREIRA (2017) revela uma dimensão que circunda o discurso da humanização e da participação familiar: "[...] a apropriação do tempo, dos saberes e das práticas de cuidado familiares como modelo de atenção sob o discurso da humanização e do cuidado familiar em saúde, se institui e naturaliza o precário" (FERREIRA, 2017, p. 21-22). 
A luz das reflexões empreendidas por autoras que compõem o pensamento crítico feminista, também não podemos deixar de observar que as mulheres adquirem um papel singular nas diversas dimensões de responsabilização destinada às famílias, ocupando lugar de destaque nas atividades assumidas por esta instituição. Podemos afirmar que a produção e reprodução do viver tem como um de seus primeiros atos históricos a relação estabelecida entre os sexos e a divisão do trabalho entre eles, que se estrutura sob o molde da subordinação, o que confere acentuadas desigualdades sociais ao cotidiano dos sujeitos e, especialmente, das mulheres.

Ao retornarmos aos objetivos deste estudo, é possível compreender que a concepção idealizada de família se evidencia no imaginário da população global e brasileira, assim como a expressa requisição de seu papel nas políticas públicas se materializa, gerando um ônus ainda maior às mulheres, como destacamos. Na saúde, este contexto não é diferente. Deste modo, assistimos a requisição constante e inegável dessa instituição no campo do cuidado e seu papel crucial no funcionamento da engrenagem da proteção social.

\section{CONSIDERAÇÕES FINAIS}

Como um dos primeiros resultados do estudo, evidenciamos o papel histórico desempenhado pela família na proteção social global e brasileira, família esta, que em muitas situações, se transveste na figura feminina. Por todos os cantos, vislumbramos famílias - e principalmente, mulheres - que trabalham na sustentação da vida cotidiana, oferecendo sua mão de obra, sem valor de troca, como um verdadeiro vetor para a reprodução social, especialmente em um contexto de pauperização das políticas públicas e de avanço da regressão neoliberal.

Esta lógica também se apresenta constantemente nos serviços de saúde, onde estes sujeitos assumem diversas facetas significativas. As normativas e orientações de serviços de saúde, inclusive, mantêm este direcionamento e reivindicam esta presença. Neste sentido, na particularidade brasileira, diferentes programas de saúde demonstram uma orientação que privilegia a participação das famílias no enfrentamento de problemáticas de saúde, sendo o cuidado realizado por famílias, base de sustentação da implementação de políticas sociais deste setor em nosso país. Exemplos, como o funcionamento do programa Melhor em Casa ou a composição do Guia Prático do Cuidador nos saltam aos olhos quando pensamos nessa discussão.

Na realidade brasileira, diferentes perspectivas da saúde têm mantido uma orientação que privilegia a participação das famílias no enfrentamento de problemáticas de saúde. Este fato nos instiga a refletir como os serviços, projetos e programas nesta área se organizam a partir de expectativas pautadas nos papéis típicos da família imaginária, tida como funcional (BARCELOS, 2011). Concretiza-se, assim, uma expectativa do papel que as famílias irão assumir nesta política pública, papel este que quando não correspondido, qualifica-se como algo disfuncional, naturalizando a responsabilização dessa instituição e viabilizando a desresponsabilização do Estado.

\section{REFERÊNCIAS}




\section{tempordlis

BARCELOS, Mariana. Silveira. A incorporação da família nos serviços de saúde: um debate a partir das concepções dos profissionais num hospital de alta complexidade. 2011. Dissertação (Mestrado em Serviço Social) - Universidade Federal de Santa Catarina, Florianópolis, 2011.

BEHRING, Elaine R.; BOSCHETTI, Ivanete. Política social: fundamentos e história. São Paulo: Cortez, 2007.

BERTELLI, Edilane; MOSER, Liliane. Que família é esta? Mosaico de diferenças, contradições, discriminações. Revista Em Pauta: teoria social e realidade contemporânea, Rio de Janeiro, v. 16, n. 42, 2018.

BOSCHETTI, Ivanete. Seguridade social no Brasil: conquistas e limites à sua efetivação. CONSELHO FEDERAL DE SERVIÇO SOCIAL (CFESS). (Org.). Serviço Social: direitos sociais e competências profissionais. Brasília (DF): CEAD/Ed. UnB, 2009.

BRASIL. Ministério da Saúde. Secretaria de Atenção à Saúde. Guia Prático do Cuidador. Brasília (DF): Ministério da Saúde, 2008. Disponível em: http://bvsms.saude.gov.br/bvs/publicacoes/guia_pratico_cuidador.pdf. Acesso em: 3 nov. 2020.

Brasil. Ministério da Saúde. Secretaria de Atenção à Saúde. Departamento de Atenção Básica. Caderno de atenção domiciliar. Brasília (DF): Ministério da Saúde, 2012. Disponível em: http://189.28.128.100/dab/docs/publicacoes/geral/cad_vol1.pdf. Acesso em: 26 jun. 2021.

CARLOTO, Cássia Maria. A chefia familiar feminina nas famílias monoparentais em situação de extrema pobreza. Revista Virtual Textos \& Contextos, Porto Alegre, n. 4, dez. 2005.

CAMPOS, Marta Silva; MIOTO, Regina Célia Tamaso. Política de Assistência Social e a Posição da Família na Política Social Brasileira. Ser Social, Brasília (DF), n. 12, p. 165-190, jan./jun. 2003.

CAMPOS, Marta Silvia; TEIXEIRA, Solange Maria. Gênero, família e proteção social: as desigualdades fomentadas pela política social. Revista Katálysis, Florianópolis, v. 13, n. 1, p. 20-28, 2010.

DUARTE, Elisete; EBLE, Laeticia Jensen; GARCIA, Leila Posenato. 30 anos do Sistema Único de Saúde. Editorial. Epidemiol. Serv. Saúde, Brasília (DF), v. 27, n. 1, 2018. Disponível em: https://www.scielosp.org/article/ress/2018.v27n1/e00100018/pt/. Acesso em: 26 jun. 2021.

ESPING-ANDERSEN, G. As três economias políticas do Welfare State. Lua Nova, São Paulo, n. 24, p. 84-116, 1991.

FERREIRA, Verônica Maria et al. Apropriação do tempo de trabalho das mulheres nas políticas de saúde e reprodução social: uma análise de suas tendências. 2017. Tese 


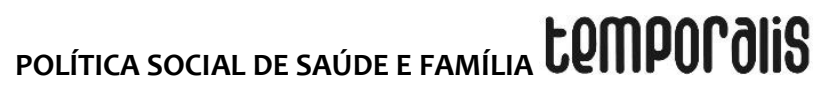

(Doutorado em Serviço Social) - Universidade Federal de Pernambuco, CCSA, Recife, 2017.

IAMAMOTO, Marilda Villela. O Serviço Social na contemporaneidade: trabalho e formação profissional. In: O SERVIÇO social na contemporaneidade: trabalho e formação profissional. São Paulo: Cortez, 2015.

MIOTO, Regina Célia Tamaso. Família e políticas sociais. In: BOSCHETTI, Ivanete et al. (Orgs.). Política social no capitalismo: tendências contemporâneas. São Paulo: Cortez, 2008.

MIOTO, Regina Célia Tamaso. Família, trabalho com famílias e Serviço Social. SERV. SOC. REV., Londrina, v. 12, n. 2, p. 163-176, jan./jun, $2010 a$.

MIOTO, Regina Célia Tamaso. Famílias e assistência Social: subsídios para o debate do trabalho dos Assistentes Sociais. In: DUARTE, M. J. O.; ALENCAR, M. M. T. (Org.). Famílias e famílias: práticas sociais e conversações contemporâneas. Rio de Janeiro: Lumen Juris, 2010b.

MIOTO, Regina Célia Tamaso. Política social e trabalho familiar: questões emergentes no debate contemporâneo. Serviço Social \& Sociedade, São Paulo: Cortez, n. 124, p. 699720, 2015.

MIOTO, Regina Célia Tamaso; CAMPOS, Marta Silva; LIMA, Telma Cristiane Sasso. Quem cobre as insuficiências das políticas públicas: contribuição ao debate sobre o papel da família na provisão de bem-estar social. Revista de Políticas Públicas, São Luís, v. 10, n. 1, p. 165-183, 2006.

MOTA, Ana Elizabete da et al. Serviço social e saúde: formação e trabalho profissional. São Paulo: Cortez, 2009.

NOGUEIRA, V. M. R. O direito à saúde na reforma do Estado brasileiro: construindo uma nova agenda. 2002. Tese (Doutorado em Enfermagem) - Programa de Pós-Graduação em Enfermagem, Universidade Federal de Santa Catarina, Florianópolis, 2002.

SKYMANSKI, Heloísa. Trabalhando com famílias. São Paulo: CBIA, 1992.

SLENES, Robert W. Lares Negros, Olhares Brancos: Histórias da Família Escrava no Século XIX. Revista Brasileira de História, São Paulo, v. 8, n. 16, 1988.

STAMM, Maristela; MIOTO, Regina Célia Tamaso. Família e cuidado: uma leitura para além do óbvio. Ciência, Cuidado e Saúde, Maringá, v. 2, n. 2, p. 161-168, jul./dez. 2003.

VASCONCELOS, Ana Maria de. A prática do Serviço Social: cotidiano, formação e alternativas na área da saúde. In: A PRÁTICA do serviço social: cotidiano, formação e alternativas na área da saúde. São Paulo: Cortez, 2012. 


\section{temPOP Olif souzA, BRUNA CRISTINA F.; ALCÂNTARA, ANA MARIA S. DE; ACQUAVIVA, GRAZIELA}

Bruna Cristina Faustino de Souza Trabalhou na concepção, delineamento, redação e revisão crítica. Graduada em Serviço Social pela Pontifícia Universidade de São Paulo (PUC-SP). Especialista em Urgência e Emergência pela Universidade Federal de São Paulo (UNIFESP). Atua como Assistente Social na atenção básica de saúde.

Ana Maria Santana de Alcântara Trabalhou na revisão crítica.

Mestre em Ciências da Saúde pela Universidade Federal de São Paulo (UNIFESP). Assistente Social da UNIFESP/Hospital São Paulo (HSP). Orientadora, tutora e preceptora da Residência Multiprofissional em Saúde da UNIFESP/HSP.

Graziela Acquaviva Trabalhou na aprovação da versão a ser publicada.

Doutorado em Serviço Social pela Pontifícia Universidade de São Paulo (PUC-SP). Professora do Departamento de Serviço Social da Faculdade de Ciências Sociais da PUC-SP. Especialista no atendimento de mulheres em situação de violência doméstica e familiar. Supervisora profissional de equipes técnicas de centro de referência e casas abrigos para mulheres.

Temporalis, Brasília (DF), ano 21, n. 41, p. 270-285, jan./jun. 2021. | ISSN 2238-1856 